
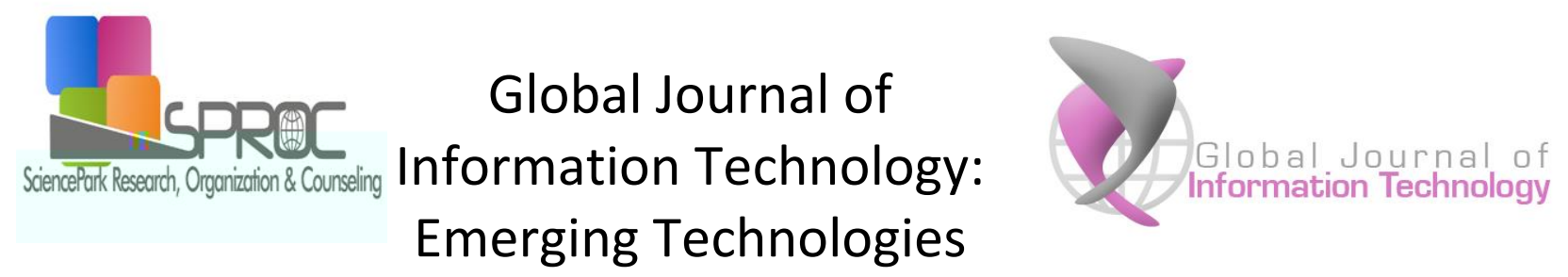

Volume 07, Issue 2, (2017) 65-70

www.gjit.eu

\title{
Technology enhanced learning in EFL classrooms
}

Lumturie Bajrami ${ }^{*}$, Department of Language Center, South East European University, Ilindenska n 335, Tetovo 1200, Macedonia

Vjosa Vela, South East European University,Ilindesnka n 335, Tetovo 1200, Macedonia

\section{Suggested Citation:}

Bajrami, L. \& Vela, V. (2017). Technology enhanced learning in EFL classrooms. Global Journal of Information Technology: Emerging Technologies. 7(2), 65-70.

Received March 27, 2017; revised June 17, 2017; accepted August 5, 2017.

Selection and peer review under responsibility of Prof. Dr. Dogan Ibrahim, Near East University, Cyprus.

${ }^{\circ} 2016$ SciencePark Research, Organization \& Counseling. All rights reserved.

\begin{abstract}
As a result of the many changes and innovations in technology, new changes and methods are used in educations and especially in language teaching. In order to offer and create successful classes language teachers, especially English language teachers are using different audio-visual tools to facilitate the teaching process, besides textbooks and other interesting and engaging activities, which ensure student centeredness, autonomy, interaction and connectivity to a certain theme, and videos such as: movies, songs, power point presentations are widely used in EFL classrooms. This paper first attempts to explore the goals of using video material in EFL classrooms and the advantages of using video materials in EFL teaching, on the basis of which proposes a framework of teaching principles, strategies and specific tips which facilitate EFL teaching. Then will bring theories and practice related to the use of audio- visual tools in language learning especially in ESP classes at South East European University and why can videos be considered as valuable pedagogical tools, to facilitate the teaching process. The purpose of this study is to investigate the benefits that the language teachers and learners get in using audio-visual aids in teaching and learning the English language, as well as to show that by using the appropriate video material the teachers can improve and ensure student-centeredness, have their students interested and engaged in activities, be more active, motivated and confident in their communicative language competence.
\end{abstract}

Keywords: language teaching, video material, EFL classroom, teaching strategies, audio-visual tools.

* ADDRESS FOR CORRESPONDENCE: Lumturie Bajrami, Department of Language Center, South East European University, Ilindenska n 335, Tetovo 1200, Macedonia

E-mail address: l.bajrami@seeu.edu.mk / Tel.: +389-75- 222-133 


\section{Introduction}

Technology in general and YouTube in particular have gained a big influence on everyone's lives and the influence that videos have in the last years in everyone's lives is undeniable. But how do we translate this medium into a practical learning tool for the classroom, without losing out on efficiency? Is the integration of technology, digital content into language a step towards the future? These are some important questions which are raised in many research studies. Video materials nowadays are not only part of everyday life activities, but they are shown as an effective method in teaching English language as a foreign language for all learners both inside and outside classroom. Ever-changing technological advancements present new opportunities for instructors to incorporate online materials, videos into traditional classroom situations, allowing both learning and teaching to become more interesting and meaningful.

A great advantage of the video materials is that they provide original and authentic input as they are produced originally for native speakers such as films, different TV programs, songs, etc. Videos can be used in variety of instructional and teaching settings- in classroom, as a way of presenting content, initiating discussion, for providing illustration for a certain topic and content, self-study and evaluation situations.

When teachers bring video materials into their English classrooms, students can directly acquire a great amount of cultural background information and emotional attitudes about the learning materials. Therefore, they could employ their autonomy in language learning. While viewing the video materials, students can put themselves in the vivid atmosphere $-34(\mathrm{~b}) 3(\mathrm{e}) 4 \mathrm{t} 3(\mathrm{l})-3 \mathrm{~F}$ by the videothematerials 2 


\section{Theoretical background}

This paper looks at the concepts of authenticity and student motivation and how they may possibly be incorporated and enhanced by using video materials as supplementary material in an EFL classroom.

Sherman (2003) presents a convincing argument for incorporating authentic video material into language classrooms. She provides a variety of practical classroom activities showing how to use video to bring real world language and culture into the classroom in contemporary, engaging and productive ways. There are lot of documentaries, educational films, interviews and sites containing a large body of material created and posted by people all over the world to communicate their ideas and beliefs, and allow for interaction with others through the commenting feature. Thus, YouTube has the potential to connect learners with authentic English input through what is quite possibly already a part of their life experience.

Videos of all kinds, as mentioned, are one readily available source of authentic pop culture material. Encouraging students to interact in an educational capacity with popular culture through English language video clips may act as a motivating factor for students wishing to further develop their language skills as they endeavor to gain a deeper understanding of content they willingly access online. Moreover, it is also available for students to engage in outside of class in some form of student-centered, self-directed learning.

According to $\mathrm{W}$. Rivers, many media and many styles of visual presentation are useful for the language learner. That is to say "all audiovisual materials have positive contributions to language learning as long as they are used at the right time, in the right place. In language learning and teaching process, learners use their eyes as well as their ears; but their eyes are basic in (p.330-340)"

Besides more typical exercises around vocabulary and grammar usage, students may be asked to write, present, or debate in English on topics, plot details, or even characters. Two minutes of presenting video material being that a news release or an ad, can provide an hour of classroom work, or it can be used to introduce a range of activities and exercises.

We know that deficiencies in vocabulary can make even a simple task very difficult for students. Another important factor for teachers that makes video materials more interesting and enjoyable is that they help to promote comprehension. Video makes the meaning clearer by illustrating everything in a way that is not possible with words, which proves the well-known saying "a picture is worth thousand words".

According to Tomalin's (1981 p.12) research, language teachers like video because it motivates learners, brings the real world into the classroom, contextualizes language naturally and enables learners to experience authentic language. Students like it because video presentations are interesting, challenging, and stimulating to watch".

Stempleski (1987 p.12-14) states, "a rich and exciting source of video software for EFL/ESL classes is authentic material." Authentic video material, especially that which represents what goes on in a non ELT environment, designed for its entertaining value rather than language teaching is a rich and exciting source of video software for instruction in English as a second language (ESL) classroom.

Using the appropriate video materials in many situations, in teaching a language lesson is aimed at helping EFL learners get oriented both in language use and some cross-cultural interactions with native speakers of English. Besides, the lesson and the accompanying activities are intended to improve EFL learners' communicative language skills (i.e., listening, speaking, reading, and writing). By 
using the videotaped segments, the main focus is on developing the learners' fluency in the process of language acquisition in a natural ongoing day-to-day interaction with native speakers.

Usually the teachers should be focused on the language, content, and production so as to meet the objectives of the learning process. For example, some certain situations require a material where the medium is "transferable to real life situations, which students are likely to come across" (Stempleki, 1987 p. 12-14).

\section{The goals of teaching English with video materials}

The effects of teaching English with video materials on students are in many cases not well matched with the efforts that teachers and students have made because teachers do not have clear goals in mind in classroom activities. It is necessary for language teachers to keep clear goals in mind in the classroom when they use video materials because they must prepare their teaching plans and implement them in reality in order to achieve their goals. Generally speaking, language teachers could set up three goals for their teaching with video materials. The first and fundamental goal is to facilitate the development of EFL learners' language skills and in particular their listening and speaking skills. Video materials provide visual aids for the listening materials that EFL learners are exposed to. When they are practicing their listening skills, learners often find it difficult to hold their attention long enough once they are exposed to long conversations or passages without visual aids. Videos can provide much more information for listeners and can keep them attention focused on the aural material. On the other hand, authentic video materials can create more realistic language learning environment and stimulate EFL learners' interest in English learning and enhance their comprehensive linguistic competence. Language learning theories state that the process of language learning includes three key parts: language input (reading and listening), assimilation (internal processing and memorization) and language output (speaking, writing and translation).

\section{The advantages of video materials in English teaching}

The use of video materials has plenty of advantages such as stimulating student's autonomy and proactivity. When teachers bring video materials into their English classrooms, students can directly acquire a great amount of cultural background information and emotional attitudes about the learning materials. Therefore, they could employ their autonomy in language learning. While viewing the video materials, students can put themselves in the vivid atmosphere created by the video materials and understand the pragmatics of the language used by the characters. Compared with traditional English teaching, such courses truly put into practice the student- centred teaching strategies.

Video also can be more motivating than other forms of authentic material. Christopher and Ho (1996, pp. 86) provide another reason why this is so; it can be entertaining. Music and setting elements can make for an enjoyable experience by learners. Video movies provide topics and ideas for learners to discuss.

In order to choose video material for the classroom, topics must be chosen based on students' interest and their level of English proficiency, as well as cultural aspects. In addition, Nunan (2003) stated that the design of listening cycles is an important consideration, which involves selecting the content of the video or audio recording and dividing it into sections for presenting in stages to learners. Instructors 
can design cycles of activities in which learners can participate. The instructor should also be a reflective observer in order not to distract the learners' attention from the video. Therefore, it would be very beneficial for instructors to select video materials that are conducive to language learning. Learners are more motivated to cope with the instruction when given the opportunity to study with the use of video materials.

The advantages of using video in the EFL classroom are many and obvious. Authors point out high motivation and an enjoyable learning environment.

Thanajaro (2000) conducted a study concerning the use of authentic materials to develop listening comprehension in the English as a Second Language (ESL) classroom through analysis of the class observation and interviews with students. The results revealed that the use of authentic materials in ESL classrooms provided a positive effect on ESL student's motivation to learn the language.

Maneekul (2002) conducted a study on using authentic material and tasks to enhance listening skill for undergraduate students majoring in English. The results revealed that students' listening skill increased to a higher level when using authentic materials and tasks after watching native speakers' video programs.

Kung (2002, as cited in Lai, 2006) stated that educators "recognize that utilizing computer technology and its attached language learning programs can be convenient to create both independent and collaborative learning environments and provide students with language experiences as they 6 move through the various stages of second language acquisition (p. 1). Undoubtedly, computer technology has become the effective teaching tools for helping teachers to successfully teach second language learners as well as to provide various opportunities for students to learn cooperatively.

Videos increase oral comprehension, stimulate student interaction and communication with other classmates, promote cross cultural awareness and are adaptable for use with students at any English language proficiency level.

The usefulness of technology is almost universally recognized many proponents of using video for EFL teaching maintain that it can be successfully used for teaching culture and agree that videos stimulate students to acquire the target culture as well as language. According to Tomalin (1992) the concept of culture has given rise to a lot of debate in the literature out of many definitions symbolic cognitive behaviourist functionalist psychological sociological anthropological the two latter ones are of paramount importance to an EFL teacher.

\section{Conclusion}

According to many researchers language teachers like video because it motivates learners, brings the real world into the classroom, contextualizes language naturally and enables learners to experience authentic language. Students like it because video presentations are interesting, challenging, and stimulating to watch. This article looks at using videos as supplementary material in an EFL setting. It is hypothesized that video material can be used as authentic material input and as a motivational tool. In general, students find the experience of using video material to be interesting, relevant, beneficial and somewhat motivating in class. As a result, it may be suggested that both teachers and students can be involved in creative ways to incorporate different video materials in a variety of classroom activities to enhance learning outcomes and provide a positive classroom environment. However, using videos in class to 
motivate students to use websites as a medium to study English outside of class and develop some degree of learner autonomy remains less clear. While teacher guidance is recommended, it is important to allow students freedom to explore on their own and take the first steps toward a journey of learning English through videos.

Video can help in promoting the language learners' listening comprehension also. The structure of 